\title{
Achara Rasayana-rejuvenation without a single medicine
}

\section{Introduction}

The practice of medicine is intended to be performed, not at the physical or personal level, but also the familial as well as social level. The principles of Ayurveda are explained not only to maintain health, but also aimed at the establishment of healthy as well as happy society. For the same, several principles are being narrated by the sages of Ayurveda which give the impression as too crucial for the current society. Rasayana is one among the eight key branches of Ayurveda, aiming prevention of manifestation of the disease and also the effective management of the evolved diseases.

Rasayana as per a layman, are several selected medicines given for the purpose of rejuvenation, the use being many and varied. But for the Ayurvedic fraternity, it includes the customs, manners, deeds, behaviorisms and also the opposite diet. If such methods can be established as rejuvenators, it can be termed as Achara rasayana i.e.; Achara or customs working in the form of rasayanas and also effective in this particular sitution. Achara rasayana theory of Ayurveda definitely plays an imperative role in the current social scenario. Many of the reported misdeeds can be overcome by altering the view of the society regarding the same leading to the suggested activities, termed as Sadvritta, as per Ayurveda.

The widely reported harmful activities such as murder, kidnapping, sexual harassments, dowry deaths, child rapes, cheating, cyber crime etc. are on the rise. The principles mentioned under Achara rasayana seems obliging in this area to a great extend. These are instructions about virtuous behaviors which are necessary to develop a healthy as well as happy society. It gives a clear cut idea about "what to do and what not to do" based on the situation. It also aims in the path to calmness of mind which is ultimately necessary to develop spiritual aspect. Thus, one can opine that achara rasayana strengthens physical, mental, social and spiritual parts of health. Hence it contributes to a larger area than expected, in preventive medicine.

A healthy mind is the base of a healthy as well as positive behavior among all individuals, which leads to a proper as well as good control over various situations. If the behavior is not as expected in a circumstance due to ensuing stress, it may create a disturbance at the familial or even social level, which have to be kept at distance, otherwise may lead to certain physiological manifestations.

Acharya Charaka explains in his treatise, the rejuvenation effect of good quality conduct which is to be adopted by quite a few methods. The measures include be truthful, free from uneven anger, not indulge in violence, alcohol as well as sex indulgence. One must be peaceful and pleasing in his speech, practice cleanliness, with a stable as well as steady mind, regularly practice charity and offer prayer to those all respectable including teachers, parents, old aged, poor etc. One must be compassionate, empathetic, and with regular habits of sleep and awakening. The intake of ghee as well as milk is the only internal administration recommended as achara in this context. One must possess expert knowledge in rationality, free from ego, good conduct and be broad minded. Also an awareness of spiritual knowledge along with the updation of scientific knowledge is the recommendation in this aspect. Proper control of the sense organs is a key factor to be accustomed in preventive psychiatry.
Volume II Issue 4 - 2018

\author{
Jithesh Madhavan \\ Department of Kayachikitsa, Ayurveda College, Kottakkal, India
}

Correspondence: Associate professor and Head, Department of Kayachikitsa,VPSV Ayurveda College, Kottakkal, India, Tel 09447882885, Email drjitheshm@gmail.com

Received: June 28, 2018 | Published: July 19, 2018

If persons endowed with these qualities practice rejuvenation therapy, they will be furnished with all the rejuvenation effects, in an enhanced manner. These effects are classified as multitude including psychological, social, behavioral, spiritual, personal, nutritional aspect etc. The ultimate quality of a person to undergo a rejuvenation therapy is none other than a stable mind.

The mode of action may be by enhancing the physical health status, making the mind more stable and also making the social relationship more compact. A healthy and positive behavior is to be expected from a person with a healthy body as well as a peaceful mind. Achara rasayana helps the individual in getting awareness about the society and to acknowledge the role of an individual in society. The unwholesome behavior has been explained as the causative factor for many diseases in Ayurveda eg. Excess krodha is causative of hridroga or cardiac problem and also disrespect of gurus are explained as leading to skin manifestations including Kushta.

Stress is being explained as the chief contributor to the fertility problems as concluded by several reported trials. On the other side methods adopted such as music therapy, healing touch therapy, prayer and other relaxation techniques are used positively as add-on therapy in cardiac care. Anyone who wishes to practice Achara Rasayana should steer clear of the rajasa and tamasa food items and stick on to a satwika dominant diet, which is said to augment the coordination of the mental functions.

Those who fail to tag on the good conduct are prone to endure from the process of prajnaparadha, explained as the causative factor of many of the diseases according to Ayurveda. Srictly following the principles of Achara rasayana, one will be good at academics or their work place, enjoying good physical as well as mental health and leads to friendly reputation among peers. The proper circadian rhythm regulates the neurotransmitters, enhances the immune mechanism leading to proper health at all aspects. Acquiring the Vedic knowledge and its updation, lead to a sharp intellect in the individual, without even adopting a single other therapeutic measure.

\section{Conclusion}

Rasayana is a unique branch among the speacialities of Ayurveda for preventive as well as curative domains. Achara rasayana is explained on an entirely different platform with effects at multilevel without any pharmacological interventions, but the awareness among the medical community, is still at its ground level. It is being aimed to enhance the health at all its levels i.e. physical, mental, social, spiritual etc. Achara Rasayana is a right code of socio-behavioral 
conduct; it teaches us a preferred life style with defined do's and don'ts. This helps as a defensive mechanism in the prevention of many a psychological illness. Practicing these techniques helps to avoid stimuli or circumstances that disturb the biological rhythms and also leads to emotional harmony. By following these codes and conducts one can enhance social scenario as well as prevent majority of diseases affecting the body as well as the mind and hence lead a happy as well as healthy life. We can plan a better nation by enhancing the skills of the future generation by enhancing their skills in a positive manner, by adopting the ancient techniques such as achara rasayana.
Further observational studies are suggested in this regard as it seems a cost effective strategy to condense the global burden of the disease.

\section{Acknowledgements}

None.

\section{Conflict of interest}

The author declares no conflict of interest. 